Marja-Tellervo Mäkinen MD, *

Arvi Yli-Hankala MD PhD†

\title{
Respiratory compliance
during laparoscopic hiatal \\ Respiratory compliance
during laparoscopic hiatal and inguinal hernia repair
}

Purpose: Side stream spirometry with dynamic compliance displayed as pressure-volume loops, has enabled early detection of $\mathrm{CO}_{2}$ pneumothorax during pneumoperitoneum. We compared dynamic compliance profiles of two laparoscopic procedures with different patient positions.

Methods: In 26 patients, scheduled either for laparoscopic fundoplication in a head-up tilt or inguinal hemiorrhaphy in a head-down titt, dynamic compliance was measured with continuous spirometry from anaesthesia induction until skin closure. Control pressure-volume loops were saved in the horizontal position before surgery and compared with succeeding loops in the head-up / head-down tilt before pneumoperitoneum, during pneumoperitoneum in the horizontal and the tilt position, after evacuation of pneumoperitoneum in the tilt and finally in the horizontal position.

Results: Pneumoperitoneum reduced compliance in both groups by $35 \%(P<0.01)$. Head-down tilt decreased compliance by $12 \%$ before and during pneumoperitoneum $(P<0.01)$. Head-up tilt increased compliance by $4 \%$ before pneumoperitoneum $(P<0.05)$, but during pneumoperitoneum it had no effect. After evacuation of pneumoperitoneum compliance returned immediately to control in head-up tit, but remained reduced in head-down tilt and was not at control after adopting horizontal position $(P<0.05)$. Difference between the groups was significant $(P$ $<0.01$ ) in the head-up / head-down tilt before, during and immediately after pneumoperitoneum.

Conclusion: Both pneumoperitoneum and head-up and head-down positions had characteristic effects on dynamic compliance. Simultaneous display of sequential pressure-volume loops enabled immediate detection of changes in respiratory mechanics.

Objectif : La spirométrie à courant secondaire accompagnée de la compliance dynamique, exprimée par des courbes débit-volume, a permis la détection précoce du pneumothorax à $\mathrm{CO}_{2}$ pendant un pneumopéritoine. Nous avons comparé les courbes de compliance dynamique de deux chirurgies laparoscopiques avec des positions différentes des patients.

Méthodes : La compliance dynamique a été mesurée chez 26 patients, devant subir soit une fundoplication laparoscopique en position inclinée, tête plus haute, soit une hemiorraphie inguinale en position inclinée, tête plus basse, avec la spirométrie continue depuis l'induction de l'anesthésie jusqu'à la fermeture cutanée. Des courbes débit-volume témoins ont été enregistrées en position horizontale avant la chirurgie et comparées avec des courbes successives avant le pneumopéritoine en position inclinée, tête plus haute / tête plus basse, pendant le pneumopéritoine en position horizontale et en position inclinée, après l'évacuation du pneumopéritoine en position inclinée et finalement en position horizontale.

Résultats : Le pneumopéritoine a réduit la compliance de $35 \%(P<0,01)$ dans les deux groupes. La position inclinée, avec la tête plus basse, a réduit la compliance de $12 \%$ avant et pendant le pneumopéritoine $(P<0,01)$. Linclinaison, avec la tête plus haute, a augmenté la comliance de $4 \%$ avant le pneumopéritoine $(P<0,05)$, mais elle n'a pas eu d'effet pendant le pneumopéritoine. À la suite de l'évacuation du pneumopéritoine, la compliance a retrouvé immédiatement la valeur témoin de la position inclinée, tête plus haute, mais la compliance est demeurée plus faible quand la tête était plus basse et n'a pas présenté la valeur témoin après l'adoption de la position horizontale $(P<0,05)$. La différence entre les groupes était significative $(P<0,01)$ en position inclinée, tête plus haute / tête plus basse, avant, pendant et immédiatement après le pneumopértoine.

Conclusion : Le pneumopéritoine et la position inclinée avec la tête vers le haut ou vers le bas ont eu des effets caractéristiques sur la compliance dynamique. L'enregistrement simultané des courbes séquentielles débit-volume a permis la détection immédiate des changements de la fonction respiratoire.

From the Department of Anaesthesia, ${ }^{\star}$ Anaesthesia Research Group, Department of Obstetrics and Gynecology, $†$ Helsinki University Central Hospital, Helsinki, Finland.

Address correspondence to: Dr. Marja-Tellervo Mäkinen, Department of Anaesthesia, Helsinki University Central Hospital, Haartmaninkatu 4, PO Box 260 FIN-00029 Helsinki, Finland. Phone: 358-9-4712458; Fax: 358-9-4714017; E-mail: telle.makinen@netlife.fi

Accepted for Publication June 2, 1998. 
A wide range of intraabdominal surgical procedures is increasingly performed laparoscopically. Untoward consequencies may result if insufflated gas escapes from the peritoneal cavity to subcutaneous tissues or to the thoracic side of the diaphragm. One of the most frequently reported complications is pneumothorax ${ }^{1-3}$ which is occasionally bilateral. ${ }^{4,5}$ Moreover, hypercarbia and acidosis from systemic absorption of carbon dioxide ${ }^{6,7}$ or carbon dioxide embolism ${ }^{8}$ may occur.

To improve intraoperative patient safety, effective differential diagnostic methods are required for immediate detection and management of respiratory complications during laparoscopy. ${ }^{9}$ Side stream spirometry, with graphic pressure-volume loops affording immediate perception of changes in respiratory mechanics, provides a useful continuous surveillance method. As we have shown in a previous study, pneumothorax was repeatedly verified during laparoscopic fundoplication before any deterioration of patients' vital signs. ${ }^{10}$

There have been earlier studies concerning the changes in lung compliance during pneumoperitoneum combined with head-down or head-up patient position. Most of them have been performed during gynaecological surgery in the head-down position, or during upper abdominal surgery in the head-up position. There are no previous studies designed to allow direct comparisons of changes in lung compliance between different positions. Comparisons, however, are possible only when observations during these interventions are made under the same clinical conditions and under the same critically controlled study protocol. In the present study design observations were obtained during two different intraabdominal surgical procedures, the one using headdown and the other head-up positioning.

The purpose of this study was to provide basic data concerning the effects of pneumoperitoneum, patient tilt positioning and their combination on dynamic compliance. The measurements were performed in clinical settings, the detailed respiratory mechanic features of which have not been previously reported.

\section{Patients and methods}

The protocol was approved by the ethics committee of the Department of Anaesthesia of the Helsinki University Central Hospital and informed consent was obtained from the patients. Patients undergoing laparoscopic fundoplication of a hiatus hernia (HIA) or laparoscopic inguinal herniorrhaphy (ING) were consecutively enrolled in the study, 13 ASA I-III in each group. Any respiratory disease or body mass index over 30 were taken as exclusion criteria.

\section{Anaesthesia}

Premedication consisted of $0.13 \mathrm{mg} \cdot \mathrm{kg}^{-1}$ oxycodone and $12.5-25 \mathrm{mg}$ promethazine $\mathrm{im}$. Following $0.2 \mathrm{mg}$ glycopyrrolate anaesthesia was induced with $20 \mu \mathrm{g}^{\mathrm{kg}}{ }^{-1}$ alfentanil and $5 \mathrm{mg} \cdot \mathrm{kg}^{-1}$ thiopentone and maintained with enflurane in oxygen and air and supplemented with $20 \mu \mathrm{g} \cdot \mathrm{kg}^{-1} \cdot \mathrm{hr}^{-1}$ alfentanil infusion. Changes in heart rate and arterial blood pressures were maintained within $20 \%$ of the preinduction values with adjustments of end-tidal enflurane concentration between 0.4-1.6 vol\% and additonal increments of $0.5 \mathrm{mg}$ alfentanil. Tracheal intubation was facilitated with $0.08 \mathrm{mg} \cdot \mathrm{kg}^{-1}$ vecuronium. Neuromuscular block was maintained with 1-2 mg vecuronium doses at a level of $90-95 \%$, as evaluated by twitch response to supramaximal transcutaneous train-of-four stimulation of the ulnar nerve. Anaesthesia and neuromuscular blockade were kept constant until $10 \mathrm{~min}$ after evacuation of $\mathrm{CO}_{2}$ from the abdominal cavity and return of the patients to horizontal position.

\section{Ventilation}

The lungs were ventilated using a Sulla $808 \mathrm{~V} \circledast$ (Draegerwerk AG, Lübeck, Germany) ventilator with a rebreathing circuit incorporating a $\mathrm{CO}_{2}$ absorber. $\mathrm{A}$ continuous fresh gas flow of $4 \mathrm{~L} \cdot \mathrm{min}^{-1}\left(1.5 \mathrm{~L} \mathrm{O}_{2}\right.$ and $2.5 \mathrm{~L}$ air), and an inspiratory to expiratory ratio of $1: 2$ and zero end-expiratory pressure were applied. Expiratory tidal volume was set to $10 \mathrm{ml} \cdot \mathrm{kg}^{-1}$ and respiratory frequency adjusted to provide an end-tidal $\mathrm{CO}_{2}$ between $4.0-4.5 \%$ before the start of surgery. Thereafter, end-tidal $\mathrm{CO}_{2}$ was kept between 4 to $6 \%$ by adjusting the ventilation frequency. At the end of operation, all ventilatory settings were unaltered until the final measurements were completed.

\section{Interventions}

Carbon dioxide pneumoperitoneum was introduced and maintained with a Laparoflator Electronic 3509®. (F. M. Wiest Medizintechnik GmbH, Germany) device. Intraabdominal insufflation pressure was limited to 12 $\mathrm{mmHg}$ with computer control.

The HIA patients were placed in the lithotomy position while awake and the ING patients were supine. After anaesthetic induction, patients were tilted to a head-up or head-down position of $15^{\circ}$ and returned to the horizontal position, to study the effect of the tilting. Then, $\mathrm{CO}_{2}$ was insufflated to an intraabdominal pressure of $12 \mathrm{mmHg}$, trocars were introduced and the $15^{\circ}$ head-up or head-down position for fundoplication and herniorrhaphy patients, respectively, was accomplished. After completion of intraabdominal surgery pneumoperitoneum was evacuated. During closure of trocar ports patients were returned to the horizontal position. 
The patient position was ascertained in each case by measuring the angle of the operation table.

\section{Measurements}

Respiratory gas concentrations (inspiratory and expiratory $\mathrm{CO}_{2}, \mathrm{O}_{2}$, and enflurane \%), respiratory rate, respiratory volumes (inspiratory and expiratory tidal and minute volume), airway pressures (peak, end-inspiratory, end-expiratory), dynamic compliance of the respiratory system and graphic pressure-volume (P-V) loops were continuously determined with a Side Stream Spirometry $^{\mathrm{TM}}$ device (Capnomac Ultima SV®, Datex Instrumentarium Corp., Helsinki, Finland) incorporating a lightweight $D$-lite ${ }^{\mathrm{TM}}$ flow sensor attached on top of an endotracheal tube. ${ }^{11}$ The dynamic compliance was calculated:11,12

$$
\underset{\left(\mathrm{cmH}_{2} \mathrm{O}\right)}{\mathrm{C}\left(\mathrm{ml} \cdot \mathrm{cmH}_{2} \mathrm{O}^{-1}\right)=V \Gamma_{\exp }(\mathrm{ml}) / \mathrm{P}_{\text {plat }}\left(\mathrm{cmH}_{2} \mathrm{O}\right)-\mathrm{PEEP}}
$$

$\mathrm{C}=$ compliance, $\mathrm{VT}_{\mathrm{exp}}=$ expiratory tidal volume, $P_{\text {plat }}=$ end-inspiratory airway pressure, $\mathrm{PEEP}=$ positive end- expiratory pressure.

The preoperative control P-V loop, obtained in the horizontal position, was saved and retrieved for display simultaneously with succeeding loops. Digital compliance values and corresponding P-V loops were recorded: 1) after anaesthesia induction in the horizontal lithotomy (HIA) and supine (ING) positions, in $15^{\circ}$ head-up (HIA) and head-down (ING) positions and again in the horizontal position, 2) during pneumoperitoneum once the intraabdominal pressure of $12 \mathrm{mmHg}$ had been accomplished, after the patients were tilted to the head-up and head-down position and at $\mathbf{1 5}$ min intervals until just before deflation of $\left.\mathrm{CO}_{2}, 3\right)$ after evacuation in the head-up and headdown tilt position, in the horizontal position during

TABLE Patient data of the laparoscopic hiatal (HIA) and inguinal (ING) hernia repair groups.

\begin{tabular}{lll}
\hline GROUP & HIA & ING \\
$n$ & 13 & 13 \\
\hline Sex $(\mathrm{m} / \mathrm{f})$ & $9 / 4$ & $12 / 1$ \\
ASA $(1 / 2 / 3)$ & $10 / 1 / 2$ & $10 / 1 / 2$ \\
Age $(\mathrm{yr})$ & $51.1 \pm 14.0(24-73)$ & $48.5 \pm 15.8(15-77)$ \\
Height $(\mathrm{cm})$ & $175.0 \pm 11.0(156-189)$ & $177.9 \pm 7.8(158-187)$ \\
Weight $(\mathrm{kg})$ & $85.2 \pm 11.3(69-108)$ & $76.5 \pm 9.0(65-93)$ \\
Pneumoperitoneum & & \\
(min) & $135.5 \pm 42.4(57-217)^{\star}$ & $82.7 \pm 17.3(55-115)$ \\
Compliance & & \\
(ml.cmH $\left.\mathrm{O}^{-1}\right)$ & $61.5 \pm 13.6(35-83)$ & $69.5 \pm 8.5(57-87)$ \\
\hline
\end{tabular}

Mean \pm SD

$\star P<0.01$ between the groups closure of trocar ports and finally after completion of skin closure.

Oxygen saturation by pulse oximetry $\left(\mathrm{SpO}_{2}\right), \mathrm{ECG}$, non-invasive arterial blood pressures, core (oesophagus in the ING group, rectum in the HIA group) and skin (big toe) temperatures were also recorded (Cardiocap®, Datex).

\section{Statistics}

Data were analysed using ANOVA for repeated measures. Paired $t$ test was used for post hoc testing within groups, and unpaired T-test between groups. The values are presented as mean $\pm s d . P$ value less than 0.05 was considered statistically significant.

\section{Results}

The characteristics of the groups, with control values of compliance, are presented in Table. Surgery was completed in all study patients and postoperative recovery was uneventful.

The changes of respiratory compliance in both groups during the study period are presented in Figure $I$ as percentage from the control values.

In the HIA patients the compliance (mean \pm sd) increased by $2.9 \pm 2.2 \mathrm{ml} \cdot \mathrm{cmH}_{2} \mathrm{O}^{-1}(P<0.05)$ during the head-up tilt of $15^{\circ}$ without pneumoperitoneum. It returned to the control value after return to the horizontal position. When the pneumoperitoneum was created in the horizontal position the mean compliance decreased by $21.6 \pm 7.1 \mathrm{ml} \cdot \mathrm{cmH}_{2} \mathrm{O}^{-1}$, to $39.8 \pm$ $7.6 \mathrm{ml} \cdot \mathrm{cm} \mathrm{H}_{2} \mathrm{O}^{-1}(P<0.01)$. The head-up tilt had no effect on compliance which remained between 39.6$41.4 \mathrm{ml} \cdot \mathrm{cmH}_{2} \mathrm{O}^{-1}$ during the pneumoperitoneum period. After desufflation of $\mathrm{CO}_{2}$ the compliance returned immediately to the control level.

In the ING patients, the compliance decreased by 8.2 $\pm 2.5 \mathrm{ml} \cdot \mathrm{cmH}_{2} \mathrm{O}^{-1}(P<0.01)$ during the head-down tilt of $15^{\circ}$ without pneumoperitoneum. It returned to the control level after return to the horizontal position. The creation of the pneumoperitoneum decreased the compliance by $25.5 \pm 7.3 \mathrm{ml} \cdot \mathrm{cmH}_{2} \mathrm{O}^{-1}$ to $43.9 \pm 5.6$ $\mathrm{ml} \cdot \mathrm{cmH}_{2} \mathrm{O}^{-1}(P<0.01)$, and head-down tilt caused a further decrease of $5.2 \pm 2.0 \mathrm{ml} \cdot \mathrm{cmH}_{2} \mathrm{O}^{-1}$ to $38.8 \pm 4.7$ $\mathrm{ml} \cdot \mathrm{cmH}_{2} \mathrm{O}^{-1}(P<0.01)$. Thereafter, compliance remained between 37.1-37.8 $\mathrm{ml} \cdot \mathrm{cmH}_{2} \mathrm{O}^{-1}$ during the pneumoperitoneum period. Immediately after evacuation of the pneumoperitoneum compliance was 11.8 $\mathrm{ml} \cdot \mathrm{cmH}_{2} \mathrm{O}^{-1}$ less than control $(P<0.01)$ and at the end of the study period, $15 \mathrm{~min}$ after evacuation, 3.6 $\mathrm{ml} \cdot \mathrm{cmH}_{2} \mathrm{O}^{-1}$ less than control $(P<0.05)$.

Individual graphic pressure-volume loops from one patient in each group, characterizing dynamic compliance at control and during pneumoperitoneum in the horizontal and in head-up or head-down position, are 


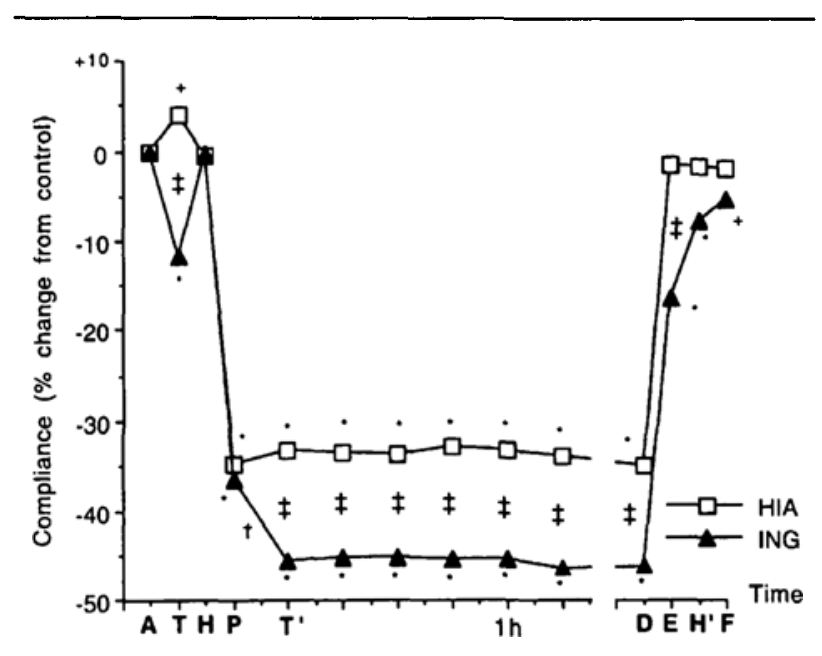

FIGURE 1 Respiratory compliance displayed as percentage change from control, during laparoscopic hiatal (HIA) and inguinal (ING) hernia repair.

$\mathbf{A}=$ control in horizontal position before pneumoperitoneum (PP), $\mathbf{T}=$ head-up / head-down tilt without $P P, \mathbf{H}=$ return to horizontal position, $\mathbf{P}=\mathbf{P P}$ created in horizontal position, $\mathbf{T}^{\prime}=$ head-up / head-down tilt during $P P, 1 \mathrm{~h}=$ one hour after creation of PP, D = start of evacuation of PP, $\mathrm{E}=\mathrm{PP}$ evacuated in head-up / head-down tilt, $\mathbf{H}^{\prime}=$ return to horizontal position, $\mathbf{F}=$ final measurement after skin closure.

$\ddagger P<0.01$ between the groups. ${ }^{*} P<0.01$ and $+P<0.05$ within each group as compared with control $A$. $\dagger P<0.01$ between $P$ and 'T' ( $=$ effect of head-down tilt during PP) in ING group.

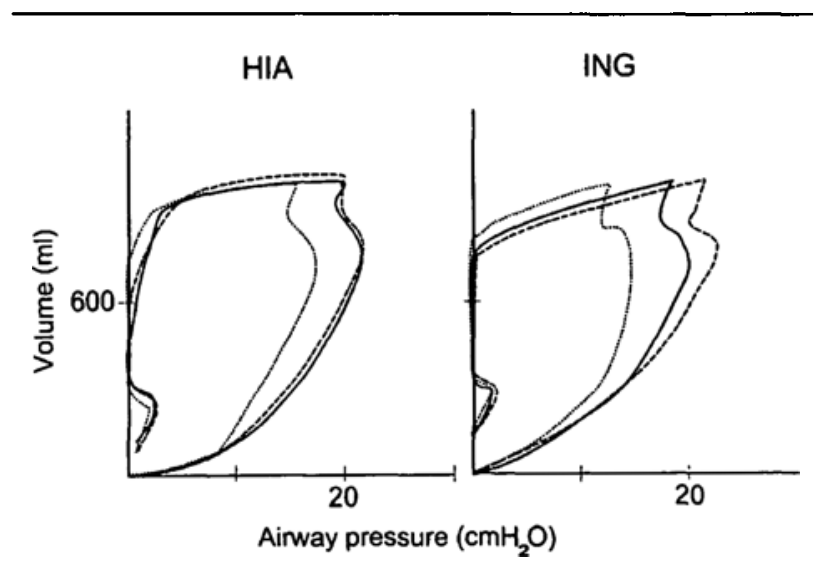

FIGURE 2 The effect of pneumoperitoneum (PP) and the combination of $\mathrm{PP}$ and patient head-up or head- down position on pressurevolume (P.V) loop configuration, in one laparoscopic hiatal (HIA) and one inguinal hernia (ING) patient.

Dotted line = control loop in horizontal position before PP. Solid line $=$ loop during PP in horizontal position. Interrupted line $=$ loop in head-up (HIA) or head-down (ING) tilt during PP.

PP caused sloping and elongation of the loop to the right: airway pressure increased, while tidal volume remained constant. Head-down tilt (ING) increased these changes, while head-up tilt (HIA) had no effect on loop configuration during PP. presented in Figure 2. Pneumoperitoneum was followed by an elongation and decline of the loop to the right. The head-down tilt in the ING group caused a further decline or sloping to the right. The head-up tilt in the HIA group had no effect.

Adjustments of respiratory frequency, to maintain end-tidal $\mathrm{CO}_{2}$ at the desired level, were not needed. Respiratory rate was similar in both groups, mean (range) 6.6 (6-9) in the HIA and 7.2 (6-9) breaths $\mathrm{min}^{-1}$ in the ING group.

During the postural and surgical procedures, inspiratory and expiratory tidal volumes did not change. Expiratory tidal volume $( \pm \mathrm{sd}$ ) was $831.7 \pm 102.4 \mathrm{ml}$ in the HIA and $801.6 \pm 102.8 \mathrm{ml}$ in the ING group before pneumoperitoneum, $819.2 \pm 112.6 \mathrm{ml}$ and $783.0 \pm$ $116.4 \mathrm{ml}$ during pneumoperitoneum and $836 \pm 105.8$ $\mathrm{ml}$ and $802.3 \pm 107.5 \mathrm{ml}$ after evacuation, respectively. Peak and end-inspiratory airway pressures increased during pneumoperitoneum and head-down tilt $(P<0.01)$. Control peak airway pressure before pneumoperitoneum was $16.2 \pm 1.8 \mathrm{cmH}_{2} \mathrm{O}$ in the HIA and $14.5 \pm$ $1.7 \mathrm{cmH}_{2} \mathrm{O}$ in the ING group. During pneumoperitoneum in the HIA group with head-up tilt it was 22.6 $\pm 2.3 \mathrm{cmH}_{2} \mathrm{O}$ and in the ING group with head-down tilt $23.0 \pm 2.7$, and, after evacuation $17.1 \pm 1.6 \mathrm{cmH}_{2} \mathrm{O}$ in the HIA and $15.7 \pm 1.9 \mathrm{cmH}_{2} \mathrm{O}$ in the ING group. Changes in airway pressures and tidal volumes were also shown by the pressure-volume loops (Figure 2). The coordinates along the $\mathrm{X}$ axis, pressure, were increased as the loops were elongated, whereas the coordinates along the $\mathrm{Y}$ axis, volume, remained constant.

\section{Discussion}

In this study, the effects of both head-up and headdown positions on dynamic compliance during various phases of two laparoscopic procedures were recorded using continuous side stream spirometry. The results showed that, without pneumoperitoneum, the effects of the positions were in the opposite direction. In the head-down position, compliance decreased by $12 \%$, while in the head-up position it increased by $4 \%(P<$ 0.01 between groups). Pneumoperitoneum reduced compliance by $35 \%$ in both groups. After that, placement in the head-down tilt further decreased compliance by $12 \%$ whereas head-up tilt did not change compliance $(P<0.01$ between groups). The levels were maintained during the pneumoperitoneum. After evacuation of the pneumoperitoneum compliance in the head-up position immediately returned to the control value whereas in head-down tilt there was incomplete recovery until adopting the horizontal position, emphasizing the role of position. 
Respiratory mechanics during pneumoperitoneum and different positions have been studied before, ${ }^{13-18}$ but there are no previous studies using protocols that allowed relevant comparisons of the changes in compliance caused by the head-down or head-up position. Therefore comparisons among different studies cannot be made. Moreover, as our results with numerous measurements obtained during the procedures show, it is important to be precise in the order of different interventions. Otherwise, interpretations concerning the relative effect of either pneumoperitoneum or position may be confusing.

The present results, concerning lung compliance during laparoscopy with head-up tilt, agree with our previous report on dynamic compliance during laparoscopic cholecystectomy ${ }^{13}$ as well as with those of a study with frequent measurements of static compliance during laparoscopic cholecystectomy. ${ }^{15}$ Head-up tilt does not improve compliance during pneumoperitoneum.

Changes of compliance during laparoscopic surgery in the head-down tilt have been recorded mostly using a protocol where pneumoperitoneum was created after placement in the head-down position. ${ }^{16-18}$ Many reports are uncertain about use of control values, as obtained either in the horizontal or in the head-down position. The combined effect of head-down tilt and pneumoperitoneum, however, seems to be similar to our results.

Side stream spirometry is most useful in detecting complications during laparoscopic surgery. It illustrates breath-by-breath changes of dynamic compliance as transformation of a graphic loop. As our present and previous $^{10,13}$ results show, decrease of compliance is indicated as an inclination to the right and as elongation along the horizontal axis. An increase of compliance is reflected as straightening of the loop to the left towards the vertical axis. These typical pressure-volume loop alterations have been referred to by others. ${ }^{3,17}$ It is possible to save up to six control loops and retain any two visible for comparison with the succeeding current loops. This enables immediate detection of changes in respiratory mechanics as transformation of the loop configuration. ${ }^{10}$ Display of previous and current loops allows simultaneous perception of changes in tidal volume, airway pressure and the corresponding compliance. The ventilatory arrangement of the present study provided constant tidal volume during pneumoperitoneum while airway pressure increased. A different ventilatory mode might give reduced tidal volume during increased intraabdominal pressure.

In conclusion, dynamic compliance was reduced during pneumoperitoneum and head-down tilt. After laparoscopic surgery, compliance returned immediately to control values in the head-up position, while delayed recovery was seen in the head-down position. Pneumoperitoneum modified the effects of patient position on compliance. Breath-by-breath pressure-volume loop served as a reliable real time monitoring tool, which instantly indicated changes in respiratory mechanics.

\section{References}

1 Reid DB, Winning T, Bell G. Pneumothorax during laparoscopic dissection of the diaphragmatic hiatus (Letter). Br J Surg 1993; 80: 670.

2 Mangar D, Kirchboff GT, Leal J, Laborde R, Fu E. Pneumothorax during laparoscopic Nissen fundoplication. Can J Anaesth 1994; 41: 854-6.

3 Joris JL, Chiche J-D, Lamy ML. Pneumothorax during laparoscopic fundoplication: diagnosis and treatment with positive end-expiratory pressure. Anesth Analg 1995; 81: 993-1000.

4 Doctor NH, Hussain Z. Bilateral pneumothorax associated with laparoscopy. A case report of a rare hazard and review of literature. Anaesthesia 1973; 28: 75-81.

5 Ferzli GS, Kiel T, Hurwitz JB, et al. Pneumothorax as a complication of laparoscopic inguinal hernia repair. Surg Endosc 1997; 11: 152-3.

6 Overdijk LE, Rademaker BM, Ringers J, Odoom JA. Laparoscopic fundoplication: a new technique with new complications? J Clin Anesth 1994; 6: 321-3.

7 Pearce DJ. Respiratory acidosis and subcutaneous emphysema during laparoscopic cholecystectomy. Can J Anaesth 1994; 41: 314-6.

8 Lantz PE, Smith JD. Fatal carbon dioxide embolism complicating attempted laparoscopic cholecystectomy case report and literature review. J Forensic Sci 1994; 39: 1468-80.

9 Wabba RWM, Tessler MJ, Kleiman SJ. Acute ventilatory complications during laparoscopic upper abdominal surgery. Can J Anaesth 1996; 43: 77-83.

10 Mäkinen M-T, Yli-Hankala A, Kansanabo M. Early detection of $\mathrm{CO}_{2}$ pneumothorax with continuous spirometry during laparoscopic fundoplication. Acta Anaesthesiol Scand 1995; 39: 411-3.

11 Side Stream spirometry ${ }^{\mathrm{TM}}$. Monitoring Patient Ventilation during Anaesthesia: Appliquide. Helsinki, Finland: DATEX Division Instrumentarium Corp., 1992, Document \#881418-1.

12 Meriläinen P, Hänninen $H$, Tuomaala L. A novel sensor for routine continuous spirometry of intubated patients. J Clin Monit 1993; 9: 374-80.

13 Mäkinen $M-T, T l i$-Hankala $A$. The effect of laparoscopic cholecystectomy on respiratory compliance as determined by continuous spirometry. J Clin Anesth 1996; 8: 119-22. 
14 Oikkonen $M$, Tallgren $M$. Changes in respiratory compliance at laparoscopy: measurements using side stream spirometry. Can J Anaesth $1995 ; 42: 495-7$.

15 Kendall AP, Bhatt $S$, Ob TE. Pulmonary consequencies of carbon dioxide insufflation for laparoscopic cholecystectomies. Anaesthesia 1995; 50: 286-9.

16 Jobannsen $G$, Andersen $M$, Jubl $B$. The effect of general anaesthesia on the haemodynamic events during laparoscopy with $\mathrm{CO}_{2}$-insufflation. Acta Anaesthesiol Scand $1989 ; 33: 132-6$.

17 Bardoczky GI, Engelman E, Levarlet $M$, Simon $P$. Ventilatory effects of pneumoperitoneum monitored with continuous spirometry. Anaesthesia 1993; 48: 309-11.

18 Hirvonen EA, Nuutinen LS, Kauko M. Ventilatory effects, blood gas changes, and oxygen consumption during laparoscopic hysterectomy. Anesth Analg 1995; 80: 961-66. 